\title{
TYPICAL MEXICAN AGROINDUSTRIAL RESIDUES AS SUPPORTS FOR SOLID-STATE FERMENTATION
}

\author{
${ }^{1}$ Dulce A. Flores-Maltos, ${ }^{2}$ Solange I. Mussatto, ${ }^{1}$ Juan C. Contreras Esquivel, \\ ${ }^{1}$ Juan J. Buenrostro, ${ }^{1}$ Raúl Rodríguez, ${ }^{2}$ José A. Teixeira and ${ }^{1}$ Cristóbal N. Aguilar
}

\begin{abstract}
${ }^{1}$ Department of Food Reacher, School of Chemistry, Universidad Autónoma de Coahuila, Saltillo, Coahuila, México ${ }^{2}$ Institute for Biotechnology and Bioengineering, Centre of Biological Engineering, University of Minho, Braga, Portugal
\end{abstract}

Received 2013-11-20; Revised 2014-02-25; Accepted 2014-03-18

\begin{abstract}
Biological wastes contain several reusable substances of high value such as soluble sugars and fiber. Direct disposal of such wastes to soil or landfill causes serious environmental problems. Thus, the development of potential value-added processes for these wastes is highly attractive. These biological wastes can be used as support-substrates in Solid-State Fermentation (SSF) to produce industrially relevant metabolites with great economical advantage. In addition, it is an environment friendly method of waste management. In this study were analyzed six different Mexican agro industrial residues to evaluate their suitability as support-substrate in SSF, between physicochemical properties that have included Water Absorption Index (WAI), Critical Moisture Point (CHP) and Packing Density (PD). The selection of an appropriate solid substrate plays an important role in the development of an efficient SSF process. The results provided important knowledge about the characteristics of these materials revealing their potential for use in fermentation processes.
\end{abstract}

Keywords: Agro-Industrial Wastes, Solid-State Fermentation, Lignocellulosic Materials

\section{INTRODUCTION}

The worldwide food, agricultural and forestry industries produce annually large volumes of wastes, which cause serious disposal problem (Rodríguez Couto, 2008). Some examples of these wastes include the bagasse and peels generated in the beverages and juice industries, coffee pulp obtained in the coffee industry and husks from the cereal industries, classified as agro industrial by-products (Graminha et al., 2008; Orzua et al., 2009). These residues are formed by lignocellulose which in turn is formed by of lignin, hemicellulose and cellulose. The chemical properties of the components of lignocellulosics make them a substrate of enormous nutritional potential and biotechnological value (Howard et al., 2003). In the last years, academic and industrial researchers are putting more and more efforts to reduce the amount of these wastes by finding alternative uses.

Solid-State Fermentation (SSF) consists on the microbial growth and product formation on the surface and at the interior of a porous solid matrix, in absence or near absence of free water (Barrios-González, 2012), is a technique used for processing and bioconversion of agroindustrial waste. A great variety of materials have been tested as solid supports for SSF, including coffee byproducts (Machado et al., 2012), rice and wheat (Khandeparkar and Bhosle, 2006), mango peels (Buenrostro-Figueroa et al., 2010), skin of grapes (Botella et al., 2007; Rodríguez et al., 2010), cranberry (Vattem and Shetty, 2003), pomegranate (Robledo et al., 2008), among others. Several of these by-products have been used as supports and/or substrates for production of metabolites of industrial interest, such as organic acids, antibiotics, pigments, flavor and aroma compounds, bioactive molecules and a great variety of enzymes (Martins et al., 2011). Biotechnology offers significant advantages, such as high concentration of metabolite obtained product stability and adaptability of microorganisms especially fungi system with low free Corresponding Author: Dulce A. Flores-Maltos, Department of Food Reacher, School of Chemistry, Universidad Autónoma de Coahuila. Saltillo, Coahuila, México 
water content (Chen, 2013; Howard et al., 2003; Pandey, 2003; Pandey et al., 1999; Shah et al., 2005).

\section{MATERIALS AND METHODS}

\subsection{Raw Materials}

The agro industrial residues used in this study were provided by Mexican local regions and included Sugarcane (Saccharis officinalis) Bagasse (SB), Coconut (Cocos nucifera) Husk (CH) Corn (Zea mays) Cobs (CC), Agave (Agave salmiana) fibers, Sotol (Dasylirion sp) and candelilla (Euphorbia antisyphilitica) stalks.

\subsection{Preparation}

The materials were pre-treated by boiling during 10 min, washed three times with distilled water and subsequently dried at $60^{\circ} \mathrm{C}$ for $24-48 \mathrm{~h}$ (Mussatto et al., 2009a) All of them were milled until to obtain a particle size of $0.60 \mathrm{~mm}$ (Orzua et al., 2009).

\subsection{Physicochemical Characterizacion}

Water Absorption Index (WAI), Critical Humidity Point (CHP) and packing density were evaluated to know the potential use as a support in SSF of fibers by agro industrial wastes.

\subsection{Water Absorption Index (WAI)}

The WAI was determined according to the methodology described by (Orzua et al., 2009). About $1.25 \mathrm{~g}$ of residue were added to $15 \mathrm{~mL}$ of distilled water and the suspension was mixed for $10 \mathrm{~min}$ and placed into a $50 \mathrm{~mL}$ measured centrifugation tube. Centrifuge was operated at $18,000 \mathrm{~g}$ for $10 \mathrm{~min}$. The supernatant was decanted and the gel weight was reported. WAI was expressed as W g gel/g dry support.

\subsection{Critical Humidity Point (CHP)}

The CHP was estimated using a thermo-balance by placing $1 \mathrm{~g}$ of sample impregnated with water at saturation (WAI result) at a temperature of $120^{\circ} \mathrm{C}$ by $60 \mathrm{~min}$.

\subsection{Packaging Density (PD)}

PD provides the material comapaction degree, therefore, the available space for mass and energy transfer. Ten grams of each material were placed in standard graduated cylinders and clamped to a shaker and vertically agitated until no change in volume during $5 \mathrm{~min}$ was observed.

\section{RESULTS}

WAI and CHP are highly relevant parameters to take into account when evaluating the potential of different materials for use as support in Solid-State Fermentation (SSF) (Mussatto et al., 2009b; Orzua et al., 2009).

WAI indicates the sample capacity to absorb water and depends on the availability of hydrophilic groups that bind water molecules and on the gel forming capacity of macromolecules (Mussatto et al., 2009a). In the present study, the highest WAI value was found in $\mathrm{CH}$, which was four times higher than those obtained for CC and CS (Fig. 1). SB was three times higher than CC and CS. No significant differences $(p \leq 0.05)$ were observed between $\mathrm{CH}$ and $\mathrm{SB}$ values. Materials with high WAI are preferred since facilitate the microorganism growth and development. For CC, WAI was similar to the values reported by Orzua et al. (2009) for $\mathrm{CH}$.

CHP represents the amount of water linked to the support, which cannot be used by the microorganism for their metabolic functions.

The materials must have low CHP to facilitate the microorganism cultivation. High values of CHP can affect the microorganism growth because a high proportion of water is bounded to the material and consequently, the microbial species development will be affected (Martins et al., 2011). Moo-Young et al. (1983) recommended a maximum limit of $\mathrm{CHP}$ at $40 \%$ for $A$. niger strains in SSF, due to the need for modification of the moisture content in relation to the absorbed media. Figure 2 shows the CHP values obtained for each waste evaluated in the present work. All supports showed CHP values below the limit reported. The high values of WAI and low values of CHP obtained for $\mathrm{AF}, \mathrm{CH}$ and $\mathrm{SB}$ reveal good potential of these materials for use in SSF processes.

Packing density is another parameter unique to SSF that can be an important process variable. It can be assumed that an increase in packing density causes a reduction in the void space between particles and a concomitant reduction in the area of exchange with the surrounding atmosphere. The lowest PD value was obtained with $\mathrm{AF}$ followed by $\mathrm{SB}$ and $\mathrm{CH}$ (Table 1), suggesting good mass and energy transfer by these materials.

Table 1. Packing Density (PD) of different agro industrial wastes

\begin{tabular}{ll}
\hline Agro industrial residues & $\mathrm{PD}\left(\mathrm{g} / \mathrm{cm}^{3}\right)$ \\
\hline Agave Fibers (AF) & 0.84 \\
Coconut Husk (CH) & 0.82 \\
Corn Cobs (CC) & 0.74 \\
Sotol Fibers (SF) & 0.80 \\
Sugarcane Bagasse (SB) & 0.83 \\
Candelilla Stalks (CS) & 0.86 \\
\hline
\end{tabular}




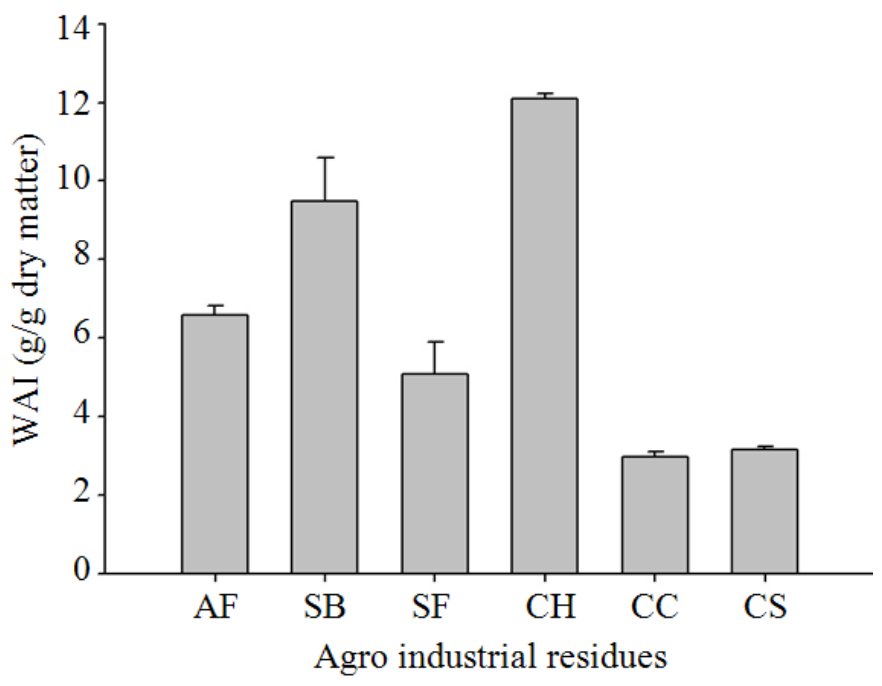

Fig. 1. Water Absorption Index (WAI) of the agro industrial residues: Agave Fibers (AF), Sugarcane Bagasse (SB), Sotol Fibers (SF), Coconut Husk (CH), Corn Cobs (CC) and Candelilla Stalks (CS)

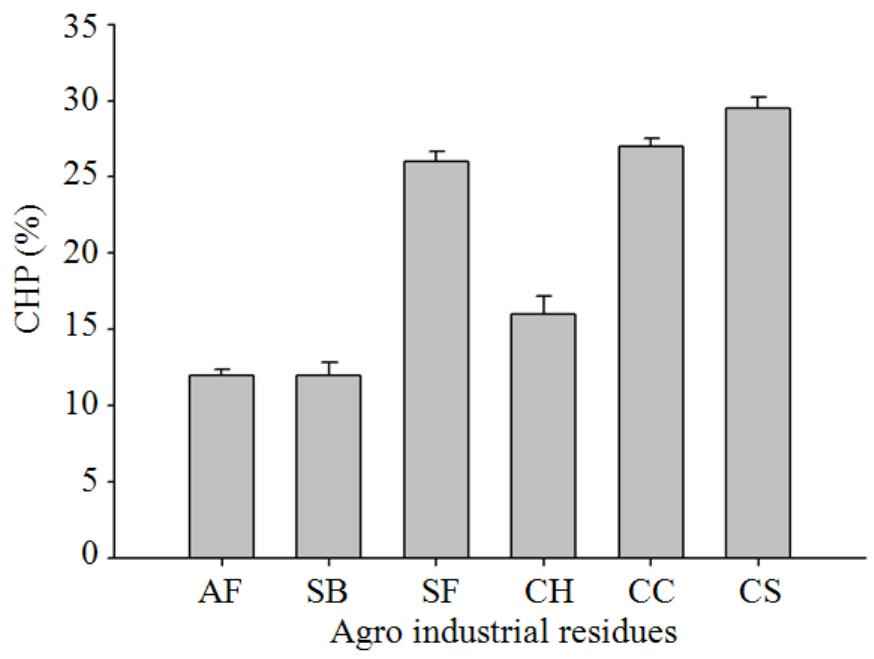

Fig. 2. Critical humidity point of the agro industrial residues: Agave Fibers (AF), Sugarcane Bagasse (SB), Sotol Fibers (SF),

Coconut Husk (CH), Corn Cobs (CC) and Candelilla Stalks (CS)

\section{DISCUSION}

The worldwide food, agricultural and forestry industries produce annually large volumes of wastes, which cause a serious disposal problem. Some examples of these wastes include the bagasse and peels generated in the beverages and juice industries, coffee pulp obtained in the coffee industry and husks from the cereal industries. Most of these residues have a nutritional potential and therefore they are receiving greater attention in terms of quality control and have been classified as agro industrial by-products.

In the last years, academic and industrial researchers are putting more and more effort to reduce the amount of these wastes by finding alternative uses. Due to the composition rich in sugars, which due to their organic nature are easily assimilated by the microorganisms; they could be appropriate for use as raw materials in the 
production of industrially-relevant compounds under Solid-State Fermentation (SSF) conditions.

The development of an efficient SSF process depends on the selection of an appropriate solid substrate (Rodríguez Couto, 2008) and thus, previous to the material use in SSF it is of great importance to determine its physical-chemical and microbiological characteristics. Two important physical-chemical parameters include the Water Absorption Index (WAI) and the Critical Humidity Point (CHP) (Robledo et al., 2008). Considering the requirements above mentioned the present study permitted to know the potential of different agro industrial wastes for use as immobilization carrier in SSF. The physical-chemical properties (WAI and CHP) will be used used as parameters to select the wastes that could be successfully reused in SSF.

\section{CONCLUSION}

Based on physical-chemical tests it could be concluded that among the 6 agro industrial residues evaluated, 3 of them, namely the agave fibers, sugarcane bagasse and coconut husk have great potential to be successfully used in SSF. In this context, the present study has focussed in the characterization of a variety of agro industrial residues for later use as a support or substrate for the production of industrially relevant metabolites. Such use would be an interesting alternative to add value to these residues besides to be of great economical advantage and an environmentalfriendly way for waste management. These facts should be taken into account when formulating a fermentation medium from these residues.

\section{ACKNOWLEDGMENT}

D.A. Flores-Maltos and J.J. Buenrostro-Figueroa thanks the Mexican National Council on Science and Technology (CONACYT) for the financial support to study their Postgraduate Program at Universidad Autónoma de Coahuila.

\section{REFERENCES}

Barrios-González, J., 2012. Solid-state fermentation: Physiology of solid medium, its molecular basis and applications. Proc. Biochem., 47: 175-185. DOI: 10.1016/j.procbio.2011.11.016

Botella, C., A. Diaz, I. De Ory, C. Webb and A. Blandino, 2007. Xylanase and pectinase production by Aspergillus awamori on grape pomace in solid state fermentation. Proc. Biochem., 42: 98-101. DOI: $10.1016 /$ j.procbio.2006.06.025
Buenrostro-Figueroa, J., H. Garza-Toledo, V. IbarraJunquera and C. Aguilar, 2010. Juice extraction from mango pulp using an enzymatic complex of Trichoderma sp. produced by solid-state fermentation. Food Sci. Biotechnol., 19: 1387-1390. DOI: 10.1007/s10068-010-0197-5

Chen, H., 2013. Principles and Application of SolidState Fermentation Carried Out on Inert Support Materials (Adsorbed Carrier Solid-State Fermentation). In: Modern Solid State Fermentation, Chen, H. (Ed.)., Springer, New York, ISBN-10: 9400760434, pp: 243-305.

Graminha, E.B.N., A.Z.L. Gonçalves, R.D.P.B. Pirota, M.A.A. Balsalobre and R. Da Silva et al., 2008. Enzyme production by solid-state fermentation: Application to animal nutrition. Animal Feed Sci. Technol., 144: 1-22. DOI: 10.1016/j.anifeedsci.2007.09.029

Howard, R.L., E. Abotsi, E.L. Jansen Van Rensburg and S. Howard, 2003. Lignocellulose biotechnology: Issues of bioconversion and enzyme production. Afri. J. Biotechnol., 2: 702-733.

Khandeparkar, R.D.S. and N.B. Bhosle, 2006. Isolation, purification and characterization of the xylanase produced by Arthrobacter sp. MTCC 5214 when grown in solid-state fermentation. Enzyme Microbial. Technol., 39: 732-742. DOI: 10.1016/j.enzmictec.2005.12.008

Machado, E.M.S., R.M. Rodriguez-Jasso, J.A. Teixeira and S.I. Mussatto, 2012. Growth of fungal strains on coffee industry residues with removal of polyphenolic compounds. Biochem. Eng. J., 60: 8790. DOI: 10.1016/j.bej.2011.10.007

Martins, S., S.I. Mussatto, G. Martínez-Avila, J. Montañez-Saenz and C.N. Aguilar et al., 2011. Bioactive phenolic compounds: Production and extraction by solid-state fermentation. Rev. Biotechnol. Adv., 29: 365-373. DOI: 10.1016/j.biotechadv.2011.01.008.

Moo-Young, M., A. Moreira and R. Tengerdy, 1983. Principles of Solid Substrate Fermentation. In: The Filamentous Fungi, Edward Arnold. Smith, J., (Eds.), London. pp: 117-144.

Mussatto, S.I., C.N. Aguilar, L.R. Rodrigues and J.A. Teixeira, 2009a. Colonization of Aspergillus japonicus on synthetic materials and application to the production of fructooligosaccharides. Carbohydrate Res., 344: 795-800. DOI: 10.1016/j.carres.2009.01.025 
Mussatto, S.I., C.N. Aguilar, L.R. Rodrigues and J.A. Teixeira, 2009b. Fructooligosaccharides and $\beta$ fructofuranosidase production by Aspergillus japonicus immobilized on lignocellulosic materials. J. Molecular Catalysis B, 59: 76-81. DOI: 10.1016/j.molcatb.2009.01.005

Orzua, M.C., S.I. Mussatto, J.C. Contreras-Esquivel, R. Rodriguez and H. de la Garza et al., 2009. Exploitation of agro industrial wastes as immobilization carrier for solid-state fermentation. Ind. Crops Products, 30: 24-27. DOI: 10.1016/j.indcrop.2009.02.001

Pandey, A., 2003. Solid-state fermentation. Biochem. Eng. J., 13: 81-84. DOI: 10.1016/S1369703X(02)00121-3

Pandey, A., P. Selvakumar, C.R. Soccol and P. Nigam, 1999. Solid state fermentation for the production of industrial enzymes. Basic Microbiol., 40: 187-197.

Robledo, A., A. Aguilera-Carbo, R. Rodriguez, J. Martinez and Y. Garza et al., 2008. Ellagic acid production by Aspergillus niger in solid state fermentation of pomegranate residues. J. Ind. Microbiol. Biotechnol., 1367-5435 35: 507-513. DOI: $10.1007 / \mathrm{s} 10295-008-0309-\mathrm{x}$
Rodríguez Couto, S., 2008. Exploitation of biological wastes for the production of value-added products under solid-state fermentation conditions. Biotechnol. J., 3: 859-870. DOI: 10.1002/biot.200800031

Rodríguez, L.A., M.E. Toro, F. Vazquez, M.L. CorreaDaneri and S.C. Gouiric et al., 2010. Bioethanol production from grape and sugar beet pomaces by solid-state fermentation. Int. J. Hydrogen Energy, 35: 5914-5917. DOI: DOI: 10.1016/j.ijhydene.2009.12.112.

Shah, M.P., G.V. Reddy, R. Banerjee, P.R. Babu and I.L. Kothari, 2005. Microbial degradation of banana waste under solid state bioprocessing using two lignocellulolytic fungi (Phylosticta spp. MPS-001 and Aspergillus spp. MPS-002). Proc. Biochem., 40: 445-451. DOI: 10.1016/j.procbio.2004.01.020

Vattem, D.A. and K. Shetty, 2003. Ellagic acid production and phenolic antioxidant activity in cranberry pomace (Vaccinium macrocarpon) mediated by Lentinus edodes using a solid-state system. Proc. Biochem., 39: 367-379. DOI: 10.1016/S0032-9592(03)00089-X 